\title{
Timo: um Relógio Vital
}

\section{Introdução}

É geralmente reconhecido que o envelhecimento começa quando cessa o crescimento e que os animais que crescem enquanto vivem, podem viver enquanto crescem. A possibilidade do envelhecimento não ocorrer em animais cujo crescimento é indeterminado é intrigante, especialmente porque não temos forma de saber se o crescimento inibe o envelhecimento ou vice-versa. Em qualquer dos casos, as implicações são muito importantes para o nosso entendimento dos mecanismos de envelhecimento e crescimento. $\mathrm{O}$ facto do corpo de alguns animais crescer ilimitadamente aponta a necessidade de saber porque outros, como os humanos, param de crescer num estádio do seu ciclo vital.

Em 1925, Bidder, reconheceu o problema de relacionar a longevidade aparente de certos peixes com as consequências de um crescimento ilimitado. Imaginemos um ser vivo em que um órgão específico cresce mais rapidamente que o corpo no seu todo. Quanto mais o animal crescer, maior a percentagem de massa corporal devida a este órgão. Numa situação limite, o resto do corpo torna-se residual. Este é um revés da imortalidade potencial.

Estes casos são férteis nos peixes. Mas nem todos os peixes possuem idade indeterminada. Os peixes que vivem em habitats de existência sasonal, possuem gerações bem determinadas. Quando os lagos secam, morre uma geração de peixes, mas a seguinte sobrevive na forma de ovos resistentes à desidratação. Ao mergulhar-se estes ovos em água, dá-se a eclosão e os novos peixes atingem a maturidade sexual em poucos meses, deixam de crescer e sucumbem no prazo de um ano, ainda que mantidos em água. Será que esta morte programada se apresenta em muitas mais espécies, ainda que de forma menos evidente? Até que ponto o envelhecimento é fruto de um desgaste de um processo obrigatório, determinado pela evolução natural? Estas questões não são fáceis e só podem ser respondidas a nível teórico, como veremos mais tarde. Por enquanto, apenas resulta da nossa observação que os peixes que crescem rapidamente até uma dimensão limitada têm um período curto de vida, enquanto que os que crescem lentamente conseguem atingir longevidades bastante superiores.

Do ponto de vista do crescimento do corpo, os animais podem ser classificados como «determinados» e «indeterminados», em que os «determinados» envelhecem e os «indeterminados» talvez não. Poder-se-á claramente pôr uma questão: Haverá qualquer razão para que todas as espécies tenham que envelhecer, desde que elas não vivam eterna- mente? O que parece importante no equilíbro da Natureza é a limitação das populações, e o envelhecimento é apenas uma forma de alcançar este objectivo surgindo assim como um fenómeno resultante de um processo adaptativo e portanto determinado geneticamente. Muitos dos invertebrados e vertebrados inferiores que são «indeterminados», se é que se lhes pode mesmo atribuir uma longevidade, habitam ambientes muito hostis e competitivos. Com todos os factores a favorecerem uma morte «violenta», não terá sido «necessário» assegurar o desfecho pelo processo de envelhecimento. Mesmo que assim não fosse, para além de certas dimensões óptimas, os animais maiores teriam problemas na obtenção de alimentos suficientes para suportar a sua estrutura.

Cada domínio da ciência tem o seu ponto de vista sobre o envelhecimento. Para a Bioquímica, até agora, parece centrar-se, principalmente, na modificação progressiva da capacidade de adaptação às modificações do ambiente. Uma abordagem experimental para o entendimento dessas alterações na homeostasia consiste em duas fases distintas, cada uma das quais incluindo um conjunto específico de finalidades. A primeira fase é descritiva por natureza, pertendendose:

- Documentar uma expressão, específica e reprodutível, da capacidade alterada;

- Localizar a origem do fenómeno dentro de uma população específica de células de um tecido;

- Identificar um acontecimento bioquímico específico cuja modificação o envelhecimento tal como documentado originalmente, é responsável, se não no todo, pelo menos em parte.

A segunda fase é mecanicista por natureza e pretende-se conhecer:

- A idade da população experimental em que se expressa a modificação bioquímica limitante pela primeira vez;

- A natureza e sequência de acontecimentos bioquímicos que precedem o aparecimento inicial da modificação numa altura específica da vida dos seres em estudo;

- A relação dos acontecimentos com outros fenómenos do envelhecimento, como por exemplo aparecimento de doenças associadas ao mesmo.

O timo é um órgão linfoepitelial, localizado no tórax, imediatamente acima do coração, junto da traqueia e aorta. É bilobulado e envolto em tecido conjuntivo, que se estende em septos pelo interior do órgão, dividindo-o em pequenos

\footnotetext{
"Centro de Bioquímica e Fisiologia Animal - INIC.

${ }^{b}$ Departamento de Química - FCL.
} 
lóbulos constituídos por duas zonas distintas, também designados retículos, sendo uma mesenquimatosa, o cortex, e a outra epitelial, a medula. A zona mais externa, o cortex, é constituída por grande número de linfócitos. As restantes são constituídas por células epiteliais.

No timo são diferenciados os linfócitos T dos mamíferos. As suas células precursoras, «stem cells», migram da medula óssea, penetram no timo e, sob acção das células epiteliais, diferenciam-se nas células T. Neste processo verifica-se elevado índice de morte celular. As células T sobreviventes são libertadas na circulação e dirigem-se para as zonas de armazenamento de células $\mathrm{T}$ nos nódulos linfáticos e outros tecidos linfáticos periféricos. As funçōes das células $\mathrm{T}$ do sistema imunitário dependem, portanto, do timo. Contudo, o timo adulto pode ser removido e as células T podem permanecer inalteradas durante períodos consideráveis devido ao facto dos locais de armazenamento das células $\mathrm{T}$ estarem permanentemente saturados e devido à longa duração das mesmas.

O timo, durante a vida de um mamífero, sofre um processo evolutivo muito particular e de grande importância para a bioquímica gerontológica uma vez que é aqui que se começam a equacionar as questões da relação timo/longevidade porque os metabolismos tímicos condicionam o desenvolvimento.

Porque ocorre o definhamento do timo? Esta questão pela sua importância obriga a que posteriormente consideremos com mais detalhe o processo de evolução deste órgão.

\section{A Bioquímica gerontológica}

A Bioquímica gerontológica é ainda uma área do conhecimento recente que procura solucionar problemas básicos. Entre estes, talvez, o mais expresso pelos investigadores seja a procura de sistemas modelo minimamente adequados ao estudo do envelhecimento.

Os animais, ou outros sistemas biológicos, manipulados, têm que possuir um certo número de condições características de envelhecimento extrapoláveis para outras espécies, principalmente a humana. Infelizmente, a bioquímica gerontológica ainda não consegue determinar quando assim acontece. Ao nível básico actual, qualquer mudança relacionada com o envelhecimento deve ser estudada.

Quanto a outras características desejáveis dos sistemas modelo, os critérios de escolha são ditados pelo bom-senso; por ex: longevidade relativamente curta, para que a logística de populações se torne menos complexa. A homogeneidade genética também é desejável, de forma que o animal testado hoje, seja essencialmente idêntico a outro da mesma idade, testado posteriormente ou anteriormente em que as diferenças entre jovens e velhos não se devam a disparidades genéticas. $\mathrm{O}$ crescimento deve ter lugar sob condições controladas para que efeitos ambientais e dietéticos sejam minimizados. Além disto, os animais não podem apresentar qualquer doença que afecte ou esconda os efeitos do envelhecimento e deve existir grande informação sobre biologia e patologia do animal.

São usados dois métodos gerais de amostragem: o de «secção cruzada» e o «longitudinal». Nos estudos que usam o primei- ro, são comparados os parâmetros medidos em animais de vários grupos etários. Nos estudos longitudinais, os mesmos indivíduos são examinados periodicamente durante certo tempo e registadas as mudanças devidas ao envelhecimento, ou à sua ausência.

\section{As modificação da adaptaçâo enzimática como expressão do envelhecimento}

Os efeitos do envelhecimento na adaptação dos enzimas podem ser expressos em 4 padrões de resposta. Algumas reacções enzimáticas são alteradas no tempo de catálise, outras na amplitude da resposta, outras em ambos os parâmetros e ainda outras são as que não sofrem qualquer alteração. Os resultados de vários tipos de experiências indicam no entanto que a capacidade modificada da adaptação dos enzimas hepáticos durante o envelhecimento não é, provavelmente, intrìnseca à função hepática. As adaptações alteradas, provavelmente, reflectem modificações dependentes do envelhecimento em mecanismos reguladores extrahepáticos. A administração de hormonas como a insulina, a glucagina e a tiroxina que estimulam as actividades enzimáticas no fígado parecem impedir a sua alteração com o envelhecimento levando-nos a pensar que a idade afectará sim os mecanismos de regulação hormonais que afectarão os mais diversos órgãos e mecanismos.

\section{Aspectos genéticos e evolutivos}

$\mathrm{O}$ essencial dos aspectos genéticos do envelhecimento poderá ser colocado nas questões seguintes:

- Quantos genes estão envolvidos no processo de envelhecimento num mamífero?

Martin fez um levantamento exaustivo das patologias apresentadas por idosos, à data do falecimento e verificou que estas patologias eram múltiplas e diversificadas do ponto de vista genético, mas que na sua maioria aparecem quase sempre associadas ao envelhecimento. Foram já descritos muitos «loci» cromossómicos associados a estas patologias e torna-se claro que uma única mutação num gene não pode originar o que se poderia chamar a «progeria global», acelerando grandemente o envelhecimento em todos os seus aspectos, ou a «antigeria global», resultando numa longevidade muito aumentada. Por ex., um dos melhores candidatos a responsável por uma progeria global é o síndroma de Werner, uma doença hereditária autossómica recessiva associada com a ateriosclerose, osteoporose, diabetes mellitus, cancro, cataratas, descoloração prematura do cabelo, perda do mesmo, entre outros aspectos do envelhecimento prematuro. O síndroma de Werner, contudo, difere do envelhecimento normal nalguns aspectos importantes: não se observa qualquer sintoma clínico ou neuropatológico do envelhecimento cerebral. Os cancros que se observam são diferentes daqueles comummente associados ao envelhecimento. Ainda assim o síndroma de Werner, com alguns outros distúrbios genéticos, pode ser um modelo valioso para aspectos específicos do processo de envelhecimento. Martin designa tais doenças genéticas por «síndromas progeróides segmentais».

Em qualquer caso, é razoável admitir que a resposta à 
questão é que talvez centenas de genes influenciem regularmente os fenotipos do envelhecimento.

- Qual o tipo de genes que está especialmente envolvido no envelhecimento? São genes reguladores ou estruturais?

Podemos argumentar que são, provavelmente, os genes reguladores segmentos de DNA que regulam outros genes e não modificam proteínas estruturais, como foi sugerido pelos trabalhos de Wilson.

A regulação de genes parece, portanto, ser de importância capital na determinação da longevidade. Segundo este autor, a evolução dos genes estruturais e a evolução morfológica, ou diferenciação, pode dar-se a taxas independentes. No caso dos mamíferos, esta última tem ocorrido a uma taxa demasiado rápida para que possa ser explicada por substituição de resíduos de aminoácidos na cadeia proteica devido a mutaçôes nos genes eșruturais. Pode ainda relacionar-se com a extensão de rearranjos cromossómicos, um processo que se pode esperar que resulte em alterações na regulação dos mesmos genes.

As classes de vertebrados com taxas mais rápidas de diferenciação também evidenciam as taxas mais rápidas de rearranjos cromossomais.

Estes resultados são consistentes com a proposta de que alterações na regulação genética, presumivelmente resultando de rearranjos cromossómicos, são determinantes para a longevidade entre os mamíferos.

- Qual a natureza da acção destes genes?

Uma possibilidade é que eles possam resultar em maiores ritmos de síntese de enzimas que mantêm a estabilidade do DNA e dos seus sistemas de transferência de informação. Há, de facto, duas linhas de experimentação que têm dado suporte àquilo que Burnet chamou «teoria da mutagénese intrínseca do envelhecimento». Esta defende que os «loci» genéticos que contribuem para a variação das longevidades máximas entre espécies de mamíferos são responsáveis por diferenças quantitativas nas taxas de mutações somáticas e suas consequências. Candidatos prováveis para tais «loci» incluem os genes codificantes de polimerases do DNA.

Hart e Setlow demonstraram uma correlação positiva entre a reparação do DNA, após irradiação com luz ultravioleta, e os logaritmos das longevidades máximas das espécies estudadas.

Outros «loci» relevantes para a hipótese da mutagénese intrínseca são aqueles que participam no metabolismo de vários agentes mutagénicos de origem exógena e endógena. Assim, os «loci» para as oxidases ou hidroxilases podem ser significativos, uma vez que codificam para a síntese de enzimas que convertem mutagénicos potenciais em produtos excretáveis.

\section{Mudanças funcionais e estruturais}

Ao serem consideradas abordagens possíveis de estudo para desvendar os mecanismos subjacentes ao processo de envelhecimento nos mamíferos, os investigadores normalmente preferem a restrição alimentar como forma de sondar o envelhecimento. Este tipo de trabalhos começou em 1935, com McCay quando se demonstrou que a restrição aos alimentos ingeridos aumenta a longevidade dos ratos de laboratório. Esta descoberta parece verificar-se em outras espécies de roedores. Os efeitos desta restrição na longevidade dos ratos depende da sua duração e amplitude.

A influência da quantidade total de alimentos ingeridos na longevidade dos ratos e outras espécies pode dever-se a alterações no nível de ingestão de um, ou mais, dos componentes da dieta. Uma vez que uma ingestão energeticamente reduzida altera a eficiência da utilização das proteínas da dieta e há uma relação estreita entre os metabolismos proteico e energético, temos que considerar a possível influência do teor proteico, glicídico e lipídico na longevidade. Ross e Bras propuseram uma relação directa entre a quantidade de proteína consumida e a longevidade dos ratos.

Como vimos, o envelhecimento é acompanhado pelo aparecimento de doenças neoplásicas e outras «degenerativas». A nutrição pode também influenciar a longevidade pela modificação dos padrões patológicos durante a velhice. Estas observações, no entanto, não permitem identificar os mecanismos celulares responsáveis pela alteração da longevidade e que foram afectados pela dieta.

Como veremos ainda, os radicais livres desempenham um papel importante no envelhecimento ao exercerem influência em estruturas moleculares chave, promovendo a lipoperoxidação, ligações cruzadas de proteínas, cisão de polipeptidos e modificações no DNA.

Do ponto de vista nutricional, é relevante explorar o papel dos antioxidantes, tal como o dos lípidos, considerando a fonte e teor desses lípidos. Packer e Smith realizaram um trabalho neste domínio ao demonstrarem que a longevidade de fibroblastos em cultura pode ser duplicada por adição de vitamina $\mathrm{E}$ ao meio. No entanto, outros autores não notaram qualquer efeito (de níveis elevados de vitamina E no meio) na longevidade de células humanas cultivadas,

\section{Teorias não imunitárias do envelhecimento}

\section{Teoria da catástrofe dos erros}

A hipótese da catástrofe dos erros foi proposta em 1963, e revista em 1969, por Leslie Orgel. Com a idade aparecem erros no mecanismo de síntese das proteínas que resultam na produção de proteínas alteradas. Se algumas destas proteínas, se tornarem parte do mecanismo de síntese proteica, causam mais erros na próxima geração de proteínas, e assim sucessivamente, até que ocorra uma «catástrofe».

Harriet e Gerbson obtiveram dados que apontavam para que um enzima, o isocitrato liase, em homogenatos de Turbatrix aceti, possuísse propriedades alteradas. Rothstein confirmou estes resultados com estudos em que usou o enzima livre. Contudo, este investigador concluiu que as diferenças de propriedades do enzima «velho» não se deviam a mudança na sequência mas a modificações pós-tradução.

O tipo de experimentação possível para suportar, ou não, esta teoria envolve a fidelidade da síntese proteica. Uma alteração no RNA-polimerase que o torne menos específico, ou uma mudança das condições celulares que provoque o mesmo efeito, pode levar à formação de mRNA alterado e, portanto, a enzimas alterados. Vários tipos de experiências demonstraram que a inserção de bases erradas no mRNA a partir de sequências de DNA artificiais mantém-se com 
RNA-polimerase de roedores velhos. A tradução do mRNA aparenta ser desempenhada sem perda de fidelidade em animais velhos.

Os dados parecem conclusivos: a catástrofe dos erros não ocorre durante o envelhecimento. No entanto, pode sempre argumentar-se que os erros existem, mas abaixo do nível detectado pelas técnicas correntes.

\section{Teoria do envelhecimento provocado por radicais livres}

Em 1956, Denham Harman propos que os radicais livres têm um papel principal no processo de envelhecimento através do estabelecimento de ligações cruzadas. Desta forma, componentes importantes das células, como membranas, proteínas, ou DNA, podem ser severamente danificados. Se os radicais livres são a causa de envelhecimento, então a sua produção aumenta com a idade ou as defesas contra eles decrescem em eficiência ou quantidade. Alternativamente, podem acumular-se, com o tempo, pequenos danos irreversíveis, incapacitando gradualmente o organismo.

Quanto à redução funcional dos mecanismos de protecção, muitos estudos têm sido feitos sobre os níveis do SOD (super óxido dismutase) tecidos, órgãos e espécies. Não foi encontrada qualquer redução da actividade funcional com a idade. O SOD tem sido também alvo de grande quantidade de experimentação para encontrar uma relação entre a quantidade de enzima presente e a longevidade das espécies. Nos mamíferos, encontrou-se uma correlação entre as taxas metabólicas multiplicadas pela longevidade e a quantidade de enzima, no entanto, outros enzimas envolvidos na protecção contra danos oxidativos como o glutationo peroxidase e o catalase, não apresentam.

Os danos criados pelos radicais livres incluem, em particular, danos nas membranas que, devido ao seu conteúdo em ácidos gordos insaturados, são um dos alvos preferenciais da peroxidação. Se as membranas forem danificadas por radicais livres então uma forma de protecção seria reduzir o teor em ácidos gordos insaturados. Rothstein afirma que o resultado dos poucos estudos efectuados neste domínio têm sido contraditórios.

Um dos problemas difíceis, ligados a esta ideia dos danos causados por ligações cruzadas em biomoléculas é que todos este componentes apresentam diferente «turnover». Assim, tendem, não a acumular-se, mas a desaparecer, dependendo das taxas relativas de síntese e degradação. $\mathrm{O}$ efeito mais durador, pensa-se ser os danos irreparáveis do DNA em células que não se dividem.

Os tecidos contêm muitas células que não se dividem e que têm que durar toda a vida: músculo, cérebro, nervo e células renais entre outras. Nestas células, os danos no DNA implicariam uma perda de função. Com a idade mais e mais células seriam afectadas.

Um dos produtos resultantes da lipoperoxidação é o malonaldeído, não se conseguindo ainda estabelecer uma relação convincente entre as quantidades de malonaldeído presentes nos tecidos e a idade dos organismos. Apesar de tudo, o malonaldeído pode ter um papel na formação dos «pigmentos do envelhecimento» (lipofuscina). Estes pigmentos encontram-se, na maioria das células, em quantidades variadas e são cracterizados por fluorescência na zona do amarelo- verde por acção ultravioleta e há muito que se sabe que aumentam com a idade.

Pryor propos um papel algo diferente para os radicais livres no processo de envelhecimento: os danos provocados causariam o aumento do número de patologias relacionadas com a idade.

\section{O timo como relógio biológico}

O metabolismo tímico condiciona a evolução do timo e este órgão, no seu conjunto, influencia, em maior ou menor grau, o envelhecimento. A grande questão que se põe é a de saber como pode o timo influenciar processos de envelhecimento que ocorrem bastante distanciados no tempo.

\section{A evolução do timo}

É consensual que o timo humano atinge o seu peso máximo durante a puberdade, após a qual começa a regredir. No entanto, é durante a vida fetal que a massa relativa deste órgão atinge o seu máximo. Aos 25-30 anos o timo está já no estado vestigial mas nunca desaparece completamente.

A questão da acção do timo sobre o organismo após o seu definhamento pode ser equacionada estudando a variação da quantidade e actividade das hormonas tímicas com a idade. Lewis et al dedicaram-se ao estudo desta questão e demonstraram que o plasma humano dos indivíduos de controlo contém actividade apreciável de indução de células $\mathrm{T}$ até à sétima década de idade. Esta actividade indutora foi atribuída à presença de timopoietina no plasma. $\mathrm{A}$ actividade indutora aumentou significativamente no segundo decénio de idade, quando o timo atinge o seu valor máximo absoluto, começando a observar-se um declínio na actividade, no quarto decénio de idade.

Bach et al haviam já demonstrado existirem no homem níveis circulantes significativos de uma hormona típica putativa, no quinto decénio de idade usando um bioensaio com formação de rosetas em eritrócitos de carneiro. Bach denominou esta hormona «factor tímico sérico».

Embora haja provas consideráveis, favorecendo o ponto de vista de que o microambiente tímico é necessário para a diferenciação das células T, (trabalhos de Stutman), estes resultados são desafiados por outros investigadores, segundo os quais o tecido tímico encerrado em câmaras miliporo pode reconstituir células $\mathrm{T}$ em ratos sem hormonas tímicas (trabalho de Osoba) e que a timopoietina pode induzir a diferenciação das células $\mathrm{T}$ durante a incubação in vitro (trabalho de Basch). Parece que a timopoietina é libertada na circulação em quantidades apreciáveis e este péptido de baixa massa molecular está, provavelmente, amplamente distribuído nos tecidos. Assim, se a concentração de timopoietina for suficientemente elevada, a diferenciação dos linfócitos T pode ser induzida in situ em vários tecidos, tais como: medula óssea e baço. Como estes órgãos não apresentam regressão com a idade podemos pensar, assim, num aumento de células T pós-tímicas, actuando o órgão como sistema de reserva. Sabe-se também que o número de células da medula diminui com a idade, enquanto as do cortex perduram em todas as espécies de mamíferos já estudadas. Como se atribui às células da medula a produção de hormonas e ao cortex os 
processos de diferenciação e proliferação das células prétímicas provenientes da medula óssea, tudo parece indicar que as funções tímicas se vão mantendo significativas por esta via alternativa mesmo após elevado grau de definhamento do órgão.

\section{A acçăo do timo sobre a longevidade, via sistema imune}

A primeira vez que foi levantada a possibilidade do envelhecimento estar directamente relacionado com processos autoimunes, foi em 1959, com a publicação de um trabalho de Burnet. Com o desenvolvimento do interesse nas ideias da vigilância imunológica, a relação do envelhecimento com os processos imunitários tornou-se mais óbvia.

A noção de «vigilância imunitária» começou por postular que se, entre os vertebrados superiores, existe uma função de reconhecimento e de destruição dos tecidos estranhos, o seu papel fundamental é o de proteger os seres contra o aparecimento dos cancros. Burnet completou esta teoria juntandolhe a noção de mutações somáticas como elemento causal central dos tumores espontâneos. A vigilância imunitária é assegurada graças à acção complexa e integrada do sistema imunitário, em particular pelos linfócitosT.

As mutações somáticas, tal como o nome indica, aparecem em células não germinais, em qualquer tecido. Se uma célula somática sofre uma mutação espontânea e se divide, ela dá início a uma população de descendentes, ou clones, todos portadores do novo gene.

Burnet usa muito este conceito de mutação somática para estabelecer a teoria de «vigilância imunitária». Mais recentemente serviu-se dela para estabelecer uma teoria do envelhecimento.

As células tumorais podem ser reconhecidas como diferentes por certas células do «hospedeiro». Ao nível das células somáticas, o aparecimento de mutações pode afectar os receptores de membranas e, portanto, tornar estas células antigénicas. Estas células serão, como já indicámos, destruídas pelo sistema imunitário. $\mathrm{O}$ desenvolvimento de um tumor só acontece quando a célula transformada é fracamente antigénica e não estimula eficazmente o sistema imunitário ou quando este é deficiente.

Um dos fenómenos que permite explicar a deficiência da resposta imunitária é o «limite de Hayflick»: células embrionárias humanas cultivadas in vitro, nas melhores condições possíveis dividem-se um número limitado de vezes, findo o qual acabam por morrer. As células de linhas cancerosas, tal como as bem conhecidas Hela, proliferam depois de várias dezenas de anos em meio adequado.

Williamson e Askomas demonstraram a existência in vivo do limite de Hayflick para as células responsáveis pela produção de anticorpos, os imunócitos. Burnet afirma que é justificado que hoje se considere que um imunócito, uma vez diferenciado, responderá a uma estímulo antigénico e dará início a um clone que persistirá durante 50 a 100 gerações celulares.

Para Burnet, é na quota de gerações dos imunócitos que o envelhecimento intervém e fá-lo sobretudo a nível dos imunócitos provenientes do timo ou sistema $\mathrm{T}$.
Os linfócitos T, cada um reagindo especificamente contra uma substância orgânica estranha ou antigénio, são armazenados nos gânglios linfáticos e outros locais do tecido linfático. $\mathrm{O}$ que os distingue das células $\mathrm{B}$, que derivam directamente da medula óssea, é que o linfócito T não liberta anticorpos no sangue, reage directamente com a superfície das células portadoras de antigénio e uma vez estimulado pelo antigénio adequado, produz substâncias estimulantes de efeitos múltiplos. A maior parte dos trabalhos que permitem atribuir ao timo um papel no envelhecimento são indirectos. Os trabalhos de Fabris, Pierpaoli e Sorkin trouxeram provas mais precisas. Estes autores enfatizam a possível importância do timo como relógio biológico no processo de envelhecimento do sistema linfático. É também avaliada a capacidade dos linfócitos, cuja diferenciação depende das hormonas tímicas, em evitar os processos de envelhecimento e morte prematura. Factores intrínsecos ao ser vivo, como as hormonas, determinam o nível funcional do timo e controlam o processo de envelhecimento através do seu produto celular principal, os linfócitos. Por fim, uma referência breve ao possível papel das doenças auto-imunes no processo de envelhecimento. Segundo Burnet o aumento com a idade da frequênica de auto-anticorpos e, consequentemente, das doenças auto-imunes, é um dos aspectos das insuficiências imunitárias associadas à velhice e à atrofia do timo.

Para finalizar, gostaríamos de chamar à atenção para dois aspectos importantes da bioquímica gerontológica e que só podem ser compreendidos tendo uma perspectiva global da bioquímica gerontológica. Primeiro, se o envelhecimento é determinado geneticamente e está incluído numa estratégia ecológica de sobrevivência e «perpetuação» da espécie então temos que passar a encará-lo de uma outra forma: o envelhecimento não representa um conjunto de disfunções do organismo mas sim de novas funções. Segundo, será que existe o envelhecimento ou os envelhecimentos? (i.e., de espécie para espécie ou de grupos taxonómicos para grupos taxonómicos o processo de envelhecimento é variável?) De uma forma geral toda a bioquímica gerontológica assenta na suposição de que existe o envelhecimento, pelo menos para todos os mamíferos. Se assim não acontecer grande parte do esforço já dispendido está comprometido, um vez que assenta em estudos comparativos que supõem a existência de um envelhecimento único. Esta dificuldade só vem acentuar a necessidade de não desconsiderar quaisquer aspectos que estejam directa ou indirectamente ligados ao envelhecimento, e fazer um estudo global.

Um caminho a percorrer porque nos parece bem pouco explorado e talvez com grandes possibilidades é o papel do timo como relógio biológico de longevidade.

\section{Referências}

- Goss, R.J. (1974), Persp. in Biol. Med., 17(4), 485-494.

- Carreira. M.t. (1985), Estudos sobre desenvolvimento e metabolismo do timo de rato.

- Rothsteim, M. (1986), Chem. and Eng. News, 64, 26-39.

- Utsuyama, M. and Hirokawa, K. (1989), Mech. of Ageing and Develop., 47, 175-185. 


\section{INSTITUTO SUPERIOR TÉCNICO}



A força dos 80 anos! 